\title{
Analisis Simpang Bersinyal Pada Bundaran Kantor Gubernur Pekanbaru
}

\author{
Analysis of Signalized Intersections at the Pekanbaru Governor's Office Roundabout \\ Bagus Banter*1, Abdul Kudus Zaini ${ }^{1}$, Astuti Boer ${ }^{1}$ \\ 1 Teknik Sipil, Universitas Islam Riau, Jalan Kaharuddin Nasution Km. 11 No. 113, Pekanbaru, Indonesia
}

* Corresponding Author : bagusbntr@yahoo.com

Tel.: +62-812-7574-3727; fax.: -

Received: Jan 10, 2019; Accepted: Apr 27, 2019.

DOI: 10.25299/saintis.2019.vol19(1).2811

\begin{abstract}
Abstrak
Permasalahan transportasi seperti kemacetan, polusi udara, kecelakaan, antrian maupun tundaan bisa di jumpai dengan tingkat kualitas yang rendah maupun besar. Permasalahan tersebut sering kita jumpai di beberapa kota di Indonesia termasuk di Pekanbaru. Beberapa titik kemacetan yang terjadi di Kota Pekanbaru saat pagi dan sore atau jam sibuk khususnya pada simpang bersinyal di jalan Sudirman - jalan Gajah Mada yang merupakan intesitas yang besar selalu dilewati lalu lalangnya kendaraan yang melewati dilokasi tersebut. Metode perhitungan analisis dan perencanaan yang di gunakan adalah metode Manual Kapasitas Jalan Indonesia 1997 (MKJI 1997) agar dapat mengetahui seberapa besar fungsi dari sistem kendali waktu tetap dalam menghindari kemacetan serta mengurangi resiko kecelakaan pada simpang akibat konflik lalu lintas. Dari hasil analisis menggunakan perhitungan MKJI 1997 di dapat kapasitas terbesar adalah 2375,94 smp/jam pada ruas jalan arah selatan. Panjang antrian maksimum adalah $171,171 \mathrm{~m}$ pada ruas jalan arah utara terjadi antrian panjang pada kondisi lalu lintas dan Tunda an rata-rata sebesar 1440,159 det/smp. Sehingga tingkat pelayanan simpang pada kondisi jam puncak masuk dalam katagori F/buruk sekali ( $>60$ detik/smp). Pada kondisi eksisting ketiga simpang sudah mendekati kinerja yang jenuh, dengan hasil derajat kejenuhan 1,00 (DS > 0.85) arah ruas jalan utara. Waktu Siklus Sinyal pada persimpangan tersebut adalah 95 detik, ini termasuk kedalam tipe pengaturan 4 fase 80-130 (MKJI,1997). Dari hasil analisis tersebut peneliti menyarankan perlu mengidupkan kembali countdown timer pengendara dapat memulai start berangkat lebih awal, hal ini dapat ini dapat mengurangi waktu hilang dan mengurangi kemacetan.
\end{abstract}

Kata Kunci : Derajat Kejenuhan, Kapasitas, Panjang Antrian, Tundaan Rata-rata, Waktu Siklus.

\begin{abstract}
Transportation problems such as congestion, air pollution, accidents, queues and delays can be found with low or large quality levels. We often experience this problem in several cities in Indonesia, including in Pekanbaru. Some congestion points that occur in the city of Pekanbaru in the morning and evening or rush hour, especially at the signal intersection on Sudirman street - Gajah Mada street which is a large intensity always passing the negligence of vehicles passing through the location. The method of calculation of analysis and planning used is the method of the Indonesian Road Capacity Manual 1997 (MKII 1997) in order to find out how much the function of the fixed time control system is to avoid congestion and reduce the risk of accidents due to traffic conflicts. From the results of the analysis using the MKJI 1997 calculation, the largest capacity is $2375.94 \mathrm{smp} /$ hour on the southern road segment. The maximum queue length is $171,171 \mathrm{~m}$ on the northern road segment, there is a long queue in traffic conditions and the delay is an average of 1440,159 det /smp. So that the level of service intersection at peak hour conditions is in the category F / very bad ( 60 seconds / junior). In the existing conditions the three intersections are close to saturated performance, with the result of a degree of saturation of 1.00 (DS>0.85) in the direction of the north road segment. The Signal Cycle time at the junction is 95 seconds, this is included in the 4 phase 80-130 setting type (MKJI, 1997). From the results of the analysis, the researchers suggest that it is necessary to revive the driver's countdown timer to start the start early, this can reduce the lost time and reduce congestion.
\end{abstract}

Keywords: Capacity, Cycle Time, Degree of Saturation, Delay, Queue Lengt

\section{PENDAHULUAN}

Permasalahan transportasi seperti kemacetan, polusi udara, kecelakaan, antrian maupun tundaan bisa di jumpai dengan tingkat kualitas yang rendah maupun besar. Permasalahan tersebut sering kita jumpai di beberapa kota di Indonesia termasuk di Pekanbaru [1].

Semakin berkembangnya kota menjadikan kota Pekanbaru sebuah kota besar dengan berbagai persoalan yang akan muncul salah satunya salah satunya persoalan kemacetan di kota Pekanbaru. Pertumbuhan penduduk yang tinggi di Kota Pekanbaru terutama yang disebabkan oleh migrasi atau urbanisasi di Kota
Pekanbaru bisa menjadi pemicu kemacetan di Kota Pekanbaru, dengan pertumbuhan penduduk yang tinggi, di mana setiap orang melakukan kegiatan atau aktivitas dalam rangka memenuhi keperluan ekonomi maupun keperluan sosialnya maka mereka semua butuh bergerak dari satu tempat ke tempat yang lain [2]. Dalam rangka memenuhi keperluan untuk bergerak tersebut, diperlukannya sebuah modal transportasi baik pribadi maupun umum sehingga seseorang menjadi mudah untuk berpindah dari satu tempat ke tempat yang lainnya dan dengan akses jalan yang terbatas maka hal ini akan mengakibatkan kemacetan. Beberapa titik kemacetan yang terjadi 
di Kota Pekanbaru saat pagi dan sore atau jam sibuk khususnya pada simpang bersinyal di jalan Sudirman - jalan Gajah Mada yang merupakan intesitas yang besar selalu dilewati lalu lalangnya kendaraan yang melewati dilokasi tersebut [3].

Upaya pengendalian simpang yang biasa dilakukan adalah dengan memasang lampu isyarat lalu lintas. Pada kondisi volume tertentu, sistem pengendali simpang dengan lampu lalu lintas cukup efektif. Namun apabila volume lalu lintas cukup besar yang melampaui kapasitasnya maka akan terjadi antrian panjang dan tundaan yang cukup besar [4]. Pengaturan lampu lalu lintas yang kurang tepat dapat mengganggu kelancaran sistem lalu lintas secara keseluruhan seperti bertumpuknya kendaraan pada satu atau beberapa ruas jalan sehingga kinerja simpang menjadi jelek. Penelitian ini bertujuan untuk mengevaluasi kinerja simpang pada persimpangan tersebut. Kinerja simpang bersinyal yang bagus dapat diketahui dengan melakukan survey tundaan dan panjang antrian.

Untuk mengatasi permasalahan menggunakan metode Manual Kapasitas Jalan Indonesia 1997 [4] agar dapat mengetahui seberapa besar fungsi dari sistem kendali waktu tetap dalam menghindari kemacetan serta mengurangi resiko kecelakaan pada simpang akibat konflik lalu lintas, sehingga terjamin bahwa suatu kapasistas tertentu dapat dipertahankan, bahkan selama kondisi lalu lintas pada jam puncak.

\section{Rumusan Masalah}

Permasalahan yang terjadi pada persimpangan jalan Sudirman - jalan Gajah Mada kota Pekanbaru pada saat ini adalah panjang antrian serta tundaan rata-rata yang cukup lama pada persimpangan tersebut [5].

Untuk mengatasi permasalahan diatas, melalui penulisan tugas akhir ini penulis akan mencoba menganalisa beberapa hal berikut ini :

1. Berapa besar kapasitas, panjang antrian maksimum, tundaan rata-rata, waktu siklus sinyal dan derajat kejenuhan pada persimpangan jalan Sudirman - jalan Gajah Mada kota Pekanbaru?

2. Apakah sudah sesuai dengan perhitungan panjang antrian dan tundaan yang tercantum dalam MKJI, pada persimpangan jalan Sudirman - jalan Gajah Mada kota Pekanbaru tersebut dengan kondisi yang ada?

\section{Tujuan Penelitian}

Adapun penulis meneliti tentang penganalisisan panjang antrian tundaan pada persimpangan jalan Sudirman - jalan Gajah Mada kota Pekanbaru dengan tujuan sebagai berikut :

1. Untuk mengetahui, panjang antrian maksimum, tundaan rata-rata, waktu siklus sinyal dan derajat kejenuhan yang ada pada persimpangan Jalan Sudirman - jalan Gajah Mada.

2. Mengevaluasi apakah sudah sesuai dengan perhitungan panjang antrian dan tundaan yang tercantum dalam MKJI, pada persimpangan jalan Sudirman - jalan Gajah Mada kota Pekanbaru tersebut dengan kondisi yang ada.

\section{METODE PENELITIAN}

\section{Persimpangan}

Persimpangan jalan adalah simpul pada jaringan jalan dimana ruas jalan bertemu dan lintasan arus kendaraan berpotongan.

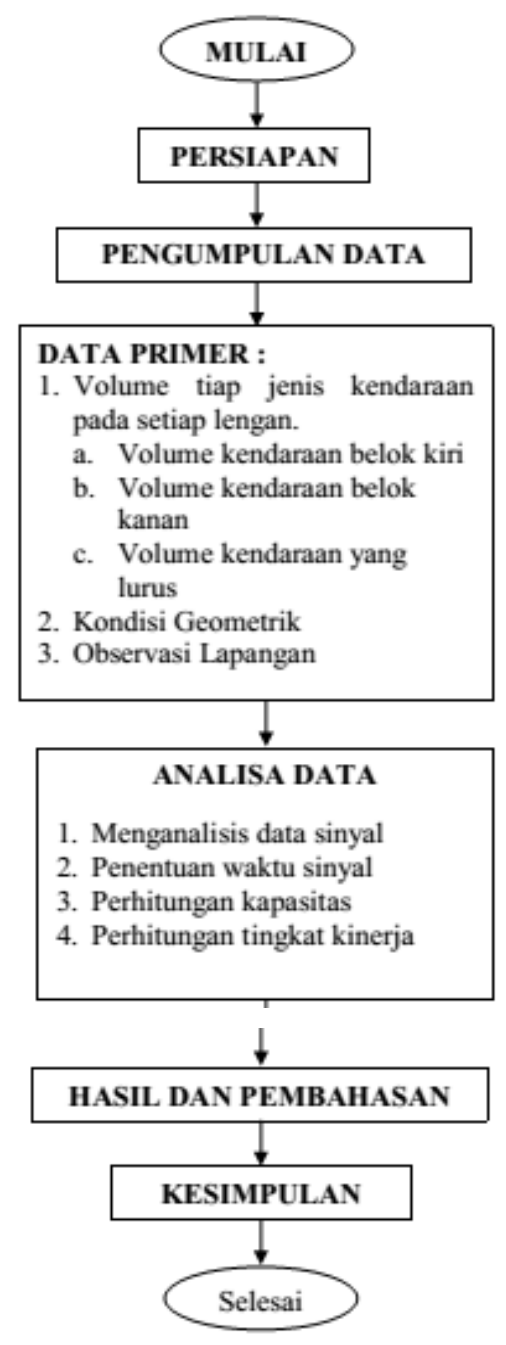

Gambar 1. Bagan Alir Penelitian

\section{Jenis jenis persimpangan}

Secara garis besarnya persimpangan terbagi dalam 2 bagian :

1. Persimpangan Sebidang.

Persimpangan sebidang adalah persimpangan dimana berbagai jalan atau ujung jalan masuk persimpangan mengarahkan lalu lintas masuk kejalan yang dapat belawanan dengan lalu lintas lainnya [4]. Pada persimpangan sebidang 
menurut jenis fasilitas pengatur lalu lintasnya dipisahkan menjadi 2 (dua) bagian :

a. Simpang bersinyal (signalised intersection) adalah persimpangan jalan yang pergerakan atau arus lalu lintas dari setiap pendekatnya diatur oleh lampu sinyal untuk melewati persimpangan secara bergilir.

b. Simpang tak bersinyal (unsignalised intersection) adalah pertemuan jalan yang tidak menggunakan sinyal pada pengaturannya.

\section{Persimpangan Tak Sebidang.}

Sedangkan persimpangan tak sebidang, sebaiknya yaitu memisah-misahkan lalu lintas pada jalur yang berbeda sedemikian rupa sehingga persimpangan jalur dari kendaraan-kendaraan hanya terjadi pada tempat dimana kendaraankendaraan memisah dari atau bergabung menjadi satu lajur gerak yang sama. (contoh jalan layang), karena kebutuhan untuk menyediakan gerakan membelok tanpa berpotongan, maka dibutuhkan tikungan yang besar dan sulit serta biayanya yang mahal. Pertemuan jalan tidak sebidang juga membutuhkan daerah yang luas serta penempatan dan tata letaknya sangat dipengaruhi oleh topografi [4].

\section{Penggunaan Sinyal}

Lampu yang mengendalikan arus lalu lintas yang terpasang di persimpangan jalan, tempat penyeberangan pejalan kaki (zebra cross), dan tempat arus lalu lintas lainnya. Lampu ini yang menandakan kapan kendaraan harus berjalan dan berhenti secara bergantian dari berbagaiarah. Pengaturan lalu lintas di persimpangan jalan dimaksudkan untuk mengatur pergerakan kendaraan pada masing-masing kelompok pergerakan kendaraan agar dapat bergerak secara bergantian sehingga tidak saling mengganggu antar-arus yang ada [6]. Penggunaan sinyal meliputi:

\section{Fase Sinyal}

Fase sinyal adalah bagian dari siklus sinyal dengan lampu hijau disediakan kombinasi tertentu dari gerakan lalulintas. Biasanya pengaturan dua fase dicoba sebagai kejadian dasar, karena biasanya menghasilkan kapasitas yang lebih besar dan tundaan rata-rata lebih rendah dari pada tipe fase sinyal lain dengan pengatur fase yang biasa dengan pengatur fase konvensional [4].

Arus berangkat belok-kanan pada fase yang berbeda dari gerakan luruslangsung memerlukan lajur (lajur RT) terpisah. Pengaturan terpisah gerakan belok kanan biasanya hanya dilakukan berdasarka pertimbangan kapasitas jika arus melebihi 200 smp/jam. Walau demikian, mungkin diperlukan demi keselamatan lalu-lintas dalam keadaan tertentu [4].

\section{Waktu Antar Hijau dan Waktu Hilang}

Waktu antar hijau didefenisikan sebagai waktu antara hijau suatu fase dan awal waktu hijau fase berikutnya. Waktu antar hijau terdiri dari waktu kuning dan waktu merah semua. Waktu merah semua yang diperlukan untuk pengosongan pada akhir setiap fase, harus memberi kesempatan bagi kendaraan terakhir (melewati garis henti pada akhir sinyal kuning) berangkat dari titik konflik sebelum kedatangan kendaraan pertama pada fase berikutnya.

\section{Penentuan Waktu Sinyal}

Penentuan waktu sinyal meliputi (MKJI,1997) adalah sebagai berikut :

1. Tipe Pendekat

Tipe pendekat pada persimpangan bersinyal umumnya dibedakan atas dua macam yaitu (MKJI,1996) :

a. Tipe terlindung (tipe P)

b. Tipe terlawan (tipe 0)

\section{Lebar Pendekatan Efektif}

Lebar efektif yaitu lebar dari bagian pendekat yang diperkeras dipergunakan dalam perhitungan kapasitas (yaitu dengan pertimbangan terhadap WA, Wmasuk dan Wexit dan gerakan lalu lintas membelok), lebar efektif (We) dapat dihitung untuk pendekatan dengan pulau lalu lintas.

3. Arus Jenuh Dasar (So)

Arus jenuh dasar (So) adalah besarnya keberangkatan antrian didalam pendekatan selama kondisi ideal (smp/jam hijau).

4. Faktor Penyesuaian

Faktor penyesuaian digunakan sebagai faktor pengali terhadap arus jenuh dasar untuk menghasilkan arus jenuh.

\section{Rasio Arus (FR)}

Rasio arus (MKJI,1997) adalah rasio arus terhadap arus jenuh (Q/S) dari suatu pendekat. Masukan arus lalu lintas yang sesuai untuk masing-masing pendekat $(\mathrm{Q})$ dengan rumus:

$$
\mathrm{FR}=\mathrm{Q} / \mathrm{S}
$$

6. Waktu Siklus

Waktu siklus (MKJI, 1997) adalah waktu urutan lengkat dari indikasi sinyal. Pada persimpangan waktu siklus merupakan fungsi dari total waktu hilang tiap siklus dan nilai banding arus dengan arus jenuh.

$$
\text { Cua }=(1,5 \times \text { LTI }+5) /(1-\text { IFR })
$$




\section{Waktu Hijau (g)}

Waktu hijau (MKJI, 1997) adalah waktu nyala hijau dalam suatu pendekat (det). Perhitungan waktu hijau tipe fase dijelaskan dengan rumus:

$$
g=(\text { Cua-LTI }) \times P R
$$

\section{Kapasitas}

Kapasitas jalan adalah jumlah kendaraan maksimum yang dapat melewati suatu jalan pada jalur jalan selama 1 jam dengan kondisi serta arus lalu lintas tertentu. Menurut (MKJI, 1997) perhitungan kapasitas (C) suatu ruas jalan perkotaan dapat dihitung dengan rumus:

$$
\mathrm{C}=\mathrm{S} \times(\mathrm{g} / \mathrm{c})
$$

\section{Derajat Kejenuhan (DS)}

Derajat kejenuhan adalah rasio arus lalu lintas terhadap kapasitas. Untuk menghitung derajat kejenuhan pada suatu ruas jalan perkotaan dengan rumus (MKJI,1997) sebagai berikut :

$$
\mathrm{DS}=\mathrm{Q} / \mathrm{C}
$$

\section{HASIL DAN PEMBAHASAN}

\section{Arus Lalu Lintas}

Dari survei yang dilakukan pada persimpangan Jalan Sudirman - Jalan Gajah Mada Pekanbaru, diperoleh data volume lalu lintas sebagai berikut:

a. Jumlah kendaraan bermotor dari arah utara adalah kendaraan dalam berbagai jenis kendaraan dan untuk kendaraan tidak bermotor berjumlah, denga waktu survei pada jam puncak dalam 1 hari (pagi, siang dan sore).

b. Jumlah kendaraan bermotor dari arah selatan adalah kendaraan dalam berbagai jenis kendaraan dan untuk kendaraan tidak bermotor berjumlah, dengan waktu survei pada jam puncak dalam 1 hari (pagi, siang dan sore).

c. Jumlah kendaraan bermotor dari arah barat adalah kendaraan dalam berbagai jenis kendaraan dan untuk kendaraan tidak bermotor berjumlah, dengan waktu survei pada jam puncak dalam 1 hari (pagi, siang dan sore).

Tabel 1. Hasil Keseluruhan Analisa Dan Perhitungan Pada Persimpangan Pada Tanggal 30 Juli 2018

\begin{tabular}{ccccccc}
\hline \multirow{2}{*}{ No } & $\begin{array}{c}\text { Kode } \\
\text { Pendekat }\end{array}$ & $\begin{array}{c}\text { Arus } \\
\text { Lalu } \\
\text { Lintas }\end{array}$ & Kapasitas & $\begin{array}{c}\text { Derajat } \\
\text { Kejenuhan } \\
\text { (DS) }\end{array}$ & $\begin{array}{c}\text { Panjang } \\
\text { Antrian } \\
\text { (QL) }\end{array}$ & $\begin{array}{c}\text { Tundaan } \\
\text { Total }\end{array}$ \\
\cline { 3 - 7 } & & (smp/jam) & & (m) & (detik/smp) \\
\hline 1 & $\mathrm{U}$ & 1681.6 & 1831.56 & 0.92 & 122.522 & 509139.71 \\
\hline 2 & $\mathrm{~T}$ & 1455.1 & 2013.92 & 0.72 & 87.272 & 66259.43 \\
\hline 3 & $\mathrm{~S}$ & 1787.8 & 2372.08 & 0.75 & 100 & 88587.28 \\
\hline
\end{tabular}

Tabel 2. Hasil Keseluruhan Analisa Dan Perhitungan Pada Persimpangan Pada Tanggal 31 Juli 2018

\begin{tabular}{ccclccc}
\hline No & $\begin{array}{c}\text { Kode } \\
\text { Pendekat }\end{array}$ & $\begin{array}{c}\text { Arus } \\
\text { Lalu } \\
\text { Lintas }\end{array}$ & Kapasitas & $\begin{array}{c}\text { Derajat } \\
\text { Kejenuhan } \\
\text { (DS) }\end{array}$ & $\begin{array}{c}\text { Panjang } \\
\text { Antrian } \\
(\mathbf{Q L})\end{array}$ & $\begin{array}{c}\text { Tundaan } \\
\text { Total }\end{array}$ \\
\cline { 2 - 7 } & & $\mathbf{( s m p / j a m )}$ & & (m) & (detik/smp) \\
\hline 1 & $\mathrm{U}$ & 1674.9 & 1826.23 & 0.92 & 122.522 & 508400.82 \\
\hline 2 & $\mathrm{~T}$ & 1452.4 & 2019.63 & 0.72 & 87.272 & 65986.89 \\
\hline 3 & $\mathrm{~S}$ & 1626.4 & 2362.71 & 0.69 & 98.333 & 52752.28 \\
\hline
\end{tabular}

Tabel 3. Hasil Keseluruhan Analisa Dan

Perhitungan Pada Persimpangan Pada Tanggal 01 Agustus 2018

\begin{tabular}{ccccccc}
\hline No & $\begin{array}{c}\text { Kode } \\
\text { Pendekat }\end{array}$ & $\begin{array}{l}\text { Arus } \\
\text { Lalu } \\
\text { Lintas }\end{array}$ & Kapasitas & $\begin{array}{c}\text { Derajat } \\
\text { Kejenuhan } \\
\text { (DS) }\end{array}$ & $\begin{array}{c}\text { Panjang } \\
\text { Antrian } \\
\text { (QL) }\end{array}$ & $\begin{array}{c}\text { Tundaan } \\
\text { Total }\end{array}$ \\
\cline { 2 - 7 } & & (smp/jam) & & (m) & (detik/smp) \\
\hline 1 & $\mathrm{U}$ & 1826.2 & 1824.97 & 1.00 & 171.171 & 2630018.37 \\
2 & $\mathrm{~T}$ & 1550.2 & 2000.90 & 0.77 & 98.181 & 102923.98 \\
3 & $\mathrm{~S}$ & 1720.4 & 2342.87 & 0.73 & 95.00 & 74524.29 \\
\hline
\end{tabular}

Tabel 4. Hasil Keseluruhan Analisa Dan

\begin{tabular}{|c|c|c|c|c|c|c|}
\hline No & $\begin{array}{c}\text { Kode } \\
\text { Pendekat }\end{array}$ & $\begin{array}{c}\text { Arus Lalu } \\
\text { Lintas }\end{array}$ & Kapasitas & $\begin{array}{c}\text { Derajat } \\
\text { Kejenuhan } \\
\text { (DS) }\end{array}$ & $\begin{array}{c}\text { Panjang } \\
\text { Antrian (QL) }\end{array}$ & $\begin{array}{c}\text { Tundaan } \\
\text { Total }\end{array}$ \\
\hline & & & (smp/jam) & & (m) & (detik/smp) \\
\hline 1 & $\mathrm{U}$ & 1781,9 & 1832,81 & 0,97 & 144,144 & 1236143,23 \\
\hline 2 & $\mathrm{~T}$ & 1374 & 2030,25 & 0,68 & 80 & 46262,58 \\
\hline 3 & $\mathrm{~S}$ & 1874,6 & 2349,48 & 0,80 & 110 & 136647,09 \\
\hline
\end{tabular}

Perhitungan Pada Persimpangan Pada Tanggal 02 Agustus 2018

Tabel 5. Hasil keseluruhan analisa dan perhitungan pada persimpangan pada tanggal 03 Agustus 2018

\begin{tabular}{ccccccc}
\hline No & $\begin{array}{c}\text { Kode } \\
\text { Pendekat }\end{array}$ & $\begin{array}{c}\text { Arus Lalu } \\
\text { Lintas }\end{array}$ & Kapasitas & $\begin{array}{c}\text { Derajat } \\
\text { Kejenuhan } \\
\text { (DS) }\end{array}$ & $\begin{array}{c}\text { Panjang } \\
\text { Antrian } \\
\text { (QL) }\end{array}$ & $\begin{array}{c}\text { Tundaan } \\
\text { Total }\end{array}$ \\
\cline { 3 - 7 } & & & (smp/jam) & & (m) & (detik/smp) \\
\hline 1 & $\mathrm{U}$ & 1716 & 1826,85 & 0,94 & 123,324 & 696038,77 \\
2 & $\mathrm{~T}$ & 1358,1 & 2018 & 0,67 & 80 & 42666,07 \\
3 & $\mathrm{~S}$ & 1574,1 & 2375,94 & 0,66 & 83,333 & 40736,13 \\
\hline
\end{tabular}

Tabel 6. Hasil keseluruhan analisa dan

\begin{tabular}{|c|c|c|c|c|c|c|}
\hline \multirow[t]{2}{*}{ No } & $\begin{array}{c}\text { Kode } \\
\text { Pendekat }\end{array}$ & $\begin{array}{l}\text { Arus Lalu } \\
\text { Lintas }\end{array}$ & Kapasitas & $\begin{array}{c}\text { Derajat } \\
\text { Kejenuhan } \\
\text { (DS) }\end{array}$ & $\begin{array}{c}\text { Panjang } \\
\text { Antrian } \\
\text { (QL) }\end{array}$ & $\begin{array}{c}\text { Tundaan } \\
\text { Total }\end{array}$ \\
\hline & & & (smp/jam) & & (m) & (detik/smp) \\
\hline 1 & U & 1665,1 & 1820,26 & 0,91 & 115,315 & 444618,33 \\
\hline 2 & $\mathrm{~T}$ & 1396,6 & 2019,63 & 0,69 & 83.636 & 50806,91 \\
\hline 3 & $\mathrm{~S}$ & 1679,1 & 2346,17 & 0,72 & 93,333 & 67603,92 \\
\hline
\end{tabular}
perhitungan pada persimpangan pada tanggal 04 Agustus 2018

Tabel 7. Hasil keseluruhan analisa dan perhitungan pada persimpangan pada tanggal 05 Agustus 2018

\begin{tabular}{ccccccc}
\hline No & $\begin{array}{c}\text { Kode } \\
\text { Pendekat }\end{array}$ & $\begin{array}{c}\text { Arus Lalu } \\
\text { Lintas }\end{array}$ & Kapasitas & $\begin{array}{c}\text { Derajat } \\
\text { Kejenuhan } \\
\text { (DS) }\end{array}$ & $\begin{array}{c}\text { Panjang } \\
\text { Antrian } \\
\text { (QL) }\end{array}$ & $\begin{array}{c}\text { Tundaan } \\
\text { Total }\end{array}$ \\
\cline { 3 - 7 } & & & (smp/jam) & & (m) & (detik/smp) \\
\hline 1 & $\mathrm{U}$ & 1329,3 & 1823,72 & 0,73 & 81,081 & 70854,35 \\
2 & $\mathrm{~T}$ & 1055,1 & 2026,98 & 0,52 & 60 & 8314,19 \\
3 & $\mathrm{~S}$ & 1246 & 2373,74 & 0,52 & 63,333 & 9929,37 \\
\hline
\end{tabular}

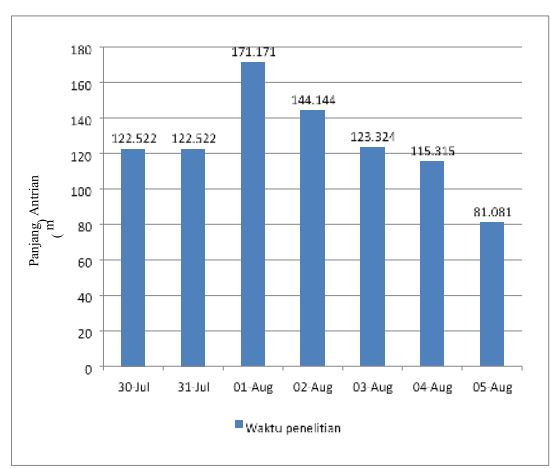

Gambar 2. Grafik Panjang Antrian Arah Utara 
Dari hasil penelitian Panjang Antrian arah Utara terbesar, dari grafik dapat dilihat pada tanggal 1 Agustus 2018 yaitu sebesar 171,171 m, tanggal 2 Agustus 2018 sebesar 144,144 m, sedangkan tanggal 3 Agustus 2018 sebesar 123,324, tanggal 30 dan 31 Juli 2018 sebesar 122,522, tanggal 4 Agustus 2018 sebesar 115,315 dan tanggal 5 Agustus 2018 memiliki antrian sebesar 81,081

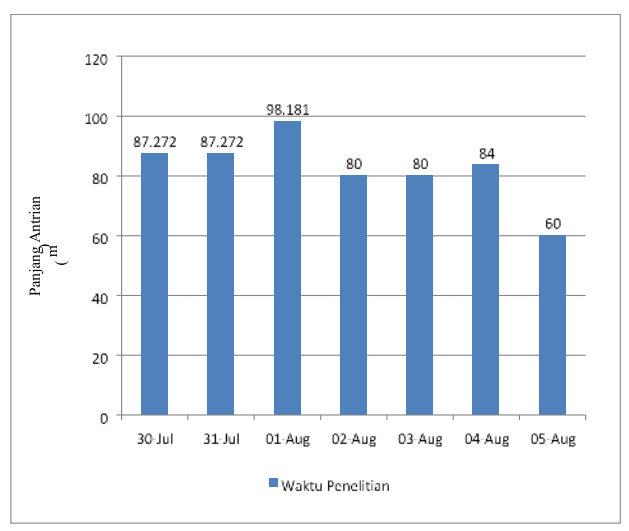

Gambar 3. Grafik Panjang Antrian Arah Timur

Dari hasil penelitian Panjang Antrian arah Timur dari grafik dapat dibuat kesimpulan bahwa aktivitas kendaraan terbesar dan menimbulkan Panjang Antrian terdapat pada tanggal 1 Agustus 2018 yaitu sebesar $98,181 \mathrm{~m}$, tanggal 30 dan 31 Juli 2018 sebesar 87,272 m, tanggal 4 Agustus sebesar $84 \mathrm{~m}$, tanggal 2 dan 3 Agustus 2018 sebesar 80 m, 5 Agustus 2018 memiliki Panjang Antrian yang dominan kecil yaitu sebesar $60 \mathrm{~m}$.

Dari hasil penelitian Panjang Antrian arah Selatan dari grafik dapat dibuat kesimpulan bahwa aktivitas kendaraan terbesar dan menimbulkan Panjang Antrian terdapat pada tanggal 2 Agustus 2018 yaitu sebesar $110 \mathrm{~m}$, tanggal 30 sebesar 100 m, tanggal 31 Juli 2018 sebesar 93,333 m, tanggal 1 Agustus 2018 sebesar 95 m, tanggal 4 Agustus 2018 sebesar 93,333 m, tanggal 3 Agustus 2018 sebesar 83,333 m, tanggal 5 Agustus 2018 memiliki Panjang antrian yang dominan kecil yaitu sebesar $63,333 \mathrm{~m}$.

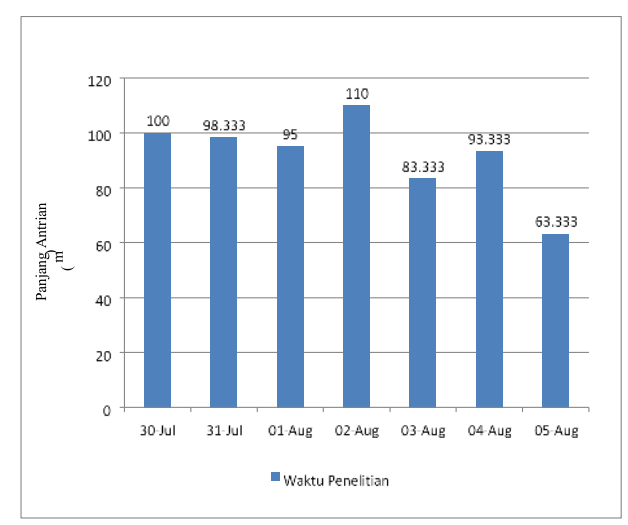

Gambar 4. Grafik Panjang Antrian Arah Selatan

Dari hasil penelitian Tundaan arah Utara dari grafik dapat dilihat Tundaan terbesar yaitu terjadi di tanggal 1 Agustus 2018 yaitu sebesar 1432,247 det/smp, tanggal 2 Agustus 2018 sebesar 686,343 det/smp, tanggal 3 Agustus 2018 sebesar 398,517 det/smp, tanggal 4 Agustus 2018 sebesar 260,093 det/smp, tanggal 31 juli 2018 sebesar 296,561 det/smp, tanggal 30 Juli 2018 sebesar 295,758 det/smp, sedangkan pada tanggal 5 Agustus 2018 memilki Tundaan yg sama kecil yaitu sebesar 46,912 det/smp

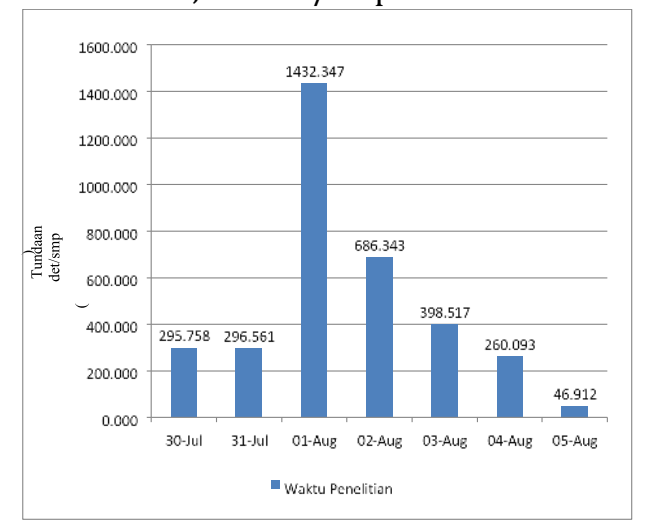

Gambar 5. Grafik Tundaan Arah Utara

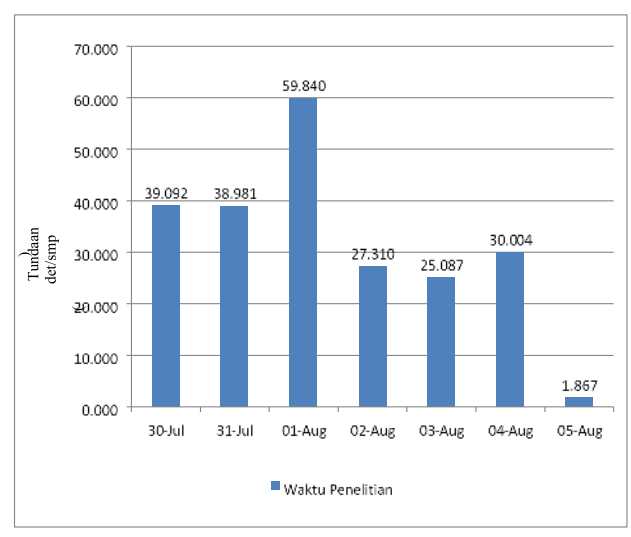

Gambar 6. Grafik Tundaan Arah Timur

Dari hasil penelitian Tundaan arah Timur dari grafik dapat dilihat Tundaan terbesar yaitu terjadi di tanggal 1 Agustus 2018 yaitu sebesar 59,840 det/smp, tanggal 30 Juli 2018 sebesar 39,092 det/smp, tanggal 31 Juli 2018 sebesar 38,981 det/smp, tanggal 4 Agustus 2018 sebesar 30,004 det/smp, tanggal 2 Agustus 2018 sebesar 27,310 det/smp, tanggal 3 Agustus 2018 sebesar $25,087 \mathrm{det} / \mathrm{smp}$, sedangkan pada tanggal 5 Agustus 2018 memilki Tundaan yg sama kecil yaitu sebesar 1,867 det/smp.

Dari hasil penelitian Tundaan arah Selatan dari grafik dapat dilihat Tundaan terbesar yaitu terjadi di tanggal 2 Agustus 2018 yaitu sebesar 65,934 det/smp, tanggal 30 Juli 2018 sebesar 42,792 det/smp, tanggal 1 Agustus 2018 sebesar 36,560 det/smp, tanggal 4 Agustus 2018 sebesar 33,556 det/smp, tanggal 31 Juli 2018 sebesar 25,648 det/smp, tanggal 3 Agustus 2018 sebesar 19,348 det/smp, sedangkan pada tanggal 5 
Agustus 2018 memiliki Tundaan yg sama kecil yaitu sebesar 1,594 det/smp.

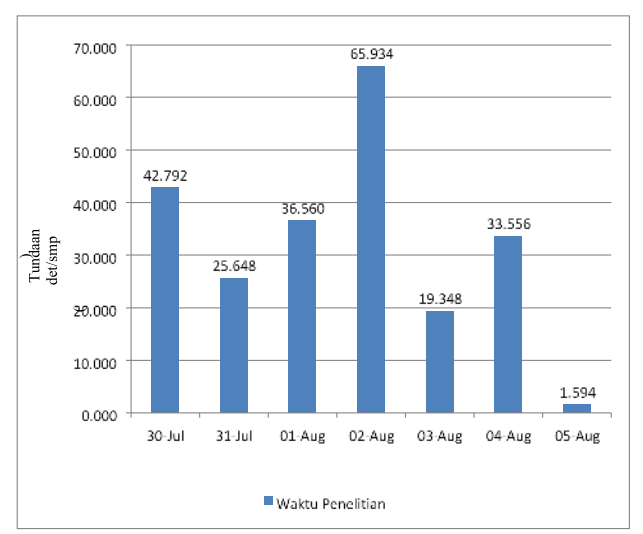

Gambar 7. Grafik Tundaan Arah Selatan

\section{KESIMPULAN DAN SARAN}

\section{Kesimpulan}

Setelah melakukan penelitian, menganalisa, membahas dan mempelajari permasalahan, maka dapat diketahui beberapa kesimpulan, yaitu :

1. Kapasitas terbesar pada persimpangan tersebut adalah $2375,94 \mathrm{smp} /$ jam pada tanggal 3 Agustus 2018 yang terdapat pada ruas jalan arah selatan. Pada tanggal 1 Agustus 2018 panjang antrian maksimum adalah $171,171 \mathrm{~m}$ pada ruas jalan arah utara, ini berarti bahwa pada simpang tersebut terjadi antrian panjang pada kondisi lalu lintas dan Tunda an rata-rata pada tanggal 1 Agustus 2018 dari simpang tersebut adalah 1440,159 det/smp yang terjadi pada ruas jalan arah utara. Sehingga tingkat pelayanan simpang pada kondisi jam puncak masuk dalam katagori F/buruk sekali ( $>60$ detik/smp). Pada kondisi eksisting ketiga simpang sudah mendekati kinerja yang jenuh, dengan hasil perhitungan derajat kejenuhan 1,00 pada tanggal 1 Agustus 2018 arah ruas jalan utara. Indikator kinerja kurang baik dimana nilai derajat kejenuhannya melebihi batas nilai derajat kejenuhan ideal (DS > 0.85). Waktu Siklus Sinyal pada persimpangan tersebut adalah 95 detik, ini termasuk kedalam tipe pengaturan 4 fase 80-130 (MKJI,1997).

2. Dari analisa persimpangan Jalan Sudirman Jalan Gajah Mada pada harihari weekday dapat dilihat bahwa kondisi persimpangan tersebut tidak sesuai dengan parameter yang ada di MKJI 1997 khusunya arah ruas jalan utara, didapat bahwa jalan yang ada dipersimpangan tersebut mengalami derajat kejenuhan yang tinggi sehingga mengakibatkan tundaan dan panjang antrian, yang di sebebkan faktor besarnya penduduk pada arah utara yang memiliki aktifitas lebih besar kearah selatan karena merupakan akses yang ideal ke bandara dan perguruan tinggi dari pada ruas jalan arah timur, pada weekend nilai volume lalu lintas persipampangan cendrung kecil dari hari biasanya karena adanya aktivitas car free day di persimpangan tersebut yang berpengaruh terhadap volume lalu lintas.

\section{Saran}

Setelah peneliti menganalisa semua permasalahan, peneliti merasa bahwa hasil yang dicapai belumlah maksimal. Hasil ini disebabkan pengamatan pengambilan data secara manual berupa fasilitas lain yang menunjang sangat terbatas. Oleh karena itu untuk kesempurnaan dalam penelitian tersebut, peneliti memberikan saran-saran sebagai berikut:

1. Perlu mengidupkan kembali countdown timer pengendara dapat memulai start berangkat lebih awal, hal ini dapat ini dapat mengurangi waktu hilang dan mengurangi kemacetan.perubahan waktu sinyal dirasa perlu untuk mengurangi jumlah tundaan yang terjadi.

\section{REFERENSI}

[1] Nasrullah, "Analisa Tundaan Dan Panjang Antrian Persimpangan Jalan Jendral Sudirman - Jalan H. Imam Munandar Pekanbaru," Teknik Sipil, Universitas Islam Riau Pekanbaru, Pekanbaru, 2007.

[2] R. W. Saputri, "Analisis Kinerja Simpang Bersinyal Jl. Pahlawan Seribu- Jl. Kapten Soebijanto Joyohadikusumo Serpong," Teknik Sipil, Universitas Mercu Buana, Serpong, 2010.

[3] A. K. Zaini, Pengantar Rekayasa Lalu Lintas. Pekanbaru: Universitas Islam Riau, 2010.

[4] (1997). Manual Kapasitas Jalan Indonesia.

[5] K. Putra, "Analisa Tundaan Dan Panjang Antrian Persimpangan Jalan Jendral Sultan Syarief Kasim - Jalan Jenderal Sudirman Dumai," Teknik Sipil Universitas Islam Riau, Pekanbaru, 2005.

[6] G. B. Citrantono, "Pengaruh Pembalikan Arah Arus Lalu Lintas Terhadap Kinerja Simpang Bersinyal Simpang Nonongan Kota Surakarta," Teknik Sipil Universitas Muhammadiyah Surakarta, Surakarta, 2014.

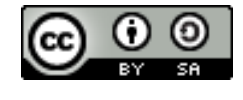

This is an open access article which means that all content is freely available without charge to the user or his/her institution. Jurnal Saintis allows the author(s) to hold the copyright without restriction. The copyright in the text of individual articles (including research articles, opinion articles, and abstracts) is the property of their respective authors distributed under the terms of the Creative Commons Attribution-ShareAlike 4.0 International License (https://creativecommons.org/licenses/by-sa/4.0/) which permits unrestricted use, distribution, and reproduction in any medium. Users are allowed to read, download, copy, distribute, search, or link to full-text articles in this journal without asking by giving appropriate credit, provide a link to the license, and indicate if changes were made. 